\title{
Is there Spillover Effect in Agricultural Industrialization Management?
}

\author{
Junyi Wan ${ }^{1} \&$ Lijun Zeng ${ }^{1}$ \\ ${ }^{1}$ College of Economics and Management, South China Agricultural University, Guangdong, China \\ Correspondence: Junyi Wan, College of Economics and Management, South China Agricultural University, \\ Guangzhou 510642, China. E-mail: jywan@scau.edu.cn
}

Received: October 25, 2017

Accepted: December 28, 2017

Online Published: December 20, 2017

doi:10.5539/ijbm.v13n1p143

URL: https://doi.org/10.5539/ijbm.v13n1p143

\begin{abstract}
China agriculture industrialization management (AIM) has made remarkable achievements in increasing cooperative farmers' income, but its impact on non-cooperative farmers excluded from the industrial management system has not caused due concern. The empirical results based on provincial level suggest the number of hierarchical agricultural management entities (HAME) have a limited influence on regional per capita gross output value of agriculture, that the driving ability of the key agricultural leading enterprises above provincial level has a significant positive impact on per capita gross output value of agriculture, that there is no statistical correlation between the indicators of driving ability and per capita household operating income of farmers. As a whole, the development level of HAME have no significant positive effect on the performance of AIM, the spillover effect of AIM is very limited. Owing to the existence of crowding out effect, AIM accelerates the differentiation between farmers within industrial management system and farmers outside the system, government need to provide more support policies for farmers outside AIM system.
\end{abstract}

Keywords: agricultural industrialization management, hierarchical agricultural management entities, spillover effect, crowding-out effect, farmer

\section{Introduction}

In the 1980s, the household contract responsibility system implemented in China greatly released the intrinsic enthusiasm of farmers' production, but it also brought the decentralized pattern of farmers' management. With the deepening agricultural products circulation system reform and the continuous development of market economy, the contradiction between small famers and big market was becoming more and more conspicuous, and the difficulty of buying and selling agricultural products happened frequently. In this context, agricultural industrialization management cooperation between farmers and other management entities came into being. The AIM is to combine small famers with some organizations at the pre-production and post-production through appropriate organizational forms, so as to solve the problem of the connection between the small famers and the large market and to enhance the comparative benefit of agricultural operation ( $\mathrm{Li}, 1998)$. The organizations at the pre-production and post-production are the leading organizations, such as agricultural enterprises and farmers' cooperatives and their cooperation with farmers can also enter the production link. Regardless of which kind of leading organization to drive the agricultural industrialization, its starting point and foothold should be to drive farmers, so the cooperative farmers must be its main body. "Leading organizations drive farmers" has become the main form of AIM and the key to AIM (Niu, 1997).

Agricultural enterprises have obvious advantages in the production and processing technology, management and market development. It has been placed in the high hopes of all walks of life and concerns; also it is supported by the government when it came into being. Also, in 2000, the government issued the "opinions on supporting key leading enterprises in the agriculture industrialization management", which clearly pointed out that "supporting leading enterprises is to support agriculture and farmers", and it defined the selection criteria for key leading enterprises and gave support to them. In addition, from 2004 to 2008, the Central Committee of the first document for five consecutive years has clearly requested the leading enterprises should be regarded as an important carrier of AIM and given great support. However, the non-equivalence of the status of the company and the farmers make the distribution of the cooperative surplus more biased to the company, and it is common for the company to encroach on the farmers' interests (Wan \& Ou, 2010). It is difficult to realize the policy goal 
of supporting agriculture and farmers by supporting the leading enterprises.

To guide farmers to carry out horizontal joint operations, encourage farmers to take the regiment to the market, enhance farmers' own organization degree, and strive to guarantee the farmers' agricultural management benefit effectively, which are based on the farmer Self Organization view to break into the market strategy receives the government attention. On July 1, 2007, the government began to implement the "Law of the people's Republic of China on Farmers' Professional Cooperation," which promotes the rapid development of cooperatives by giving them legal status and clarifying their organizational structure and supporting policies. In addition, the first document in 2007 proposed to support the development of farmers' cooperatives for the first time, and from 2008 to 2010, the third consecutive year of the first document emphasized supporting the development of farmers' cooperatives. Under the guidance and support of the government policy, the farmers' cooperatives are developing vigorously. Data from the State Administration for Industry and Commerce show that by the end of 2007, there were 26,000 farmers' cooperatives registered nationwide, and to the end of 2008, the number of farmers' cooperatives had increased rapidly to 109,900 , we can see that the increase rate is as high as 326.54 percent. By the end of April 2015, the number of Chinese farmers' cooperatives had reached 1.373 million. However, a considerable portion of the farmers' cooperatives are a set of fake cooperatives that are promoted by government policies, there are not many cooperatives that really carry out business activities and driving farmers (Pan, 2011). Even though some cooperatives normally carry out their activities, due to imperfect internal governance, the problem of "insider control" exists mostly in surplus distribution (Sun \& Yu, 2012). A few core members occupy the interests of ordinary members, and it is difficult to protect the interests of famers effectively, which deviates from the original of the government policy intention.

Along with the rapid development of industrialization and urbanization, and combined with the higher risk and low income of agricultural operation, the rural labor force is transferred to the outside, and the phenomenon of increasing combined or sideline occupations for the agricultural population, rural hollowing and the aging of rural famers is becoming more and more serious. So, "who to farm?" and "who will work" in agriculture are becoming more and more urgent. It has clearly pointed out that the key to solving this problem lies in solving the problem of people in the 2013 Central Rural Work Conference. Based on the opportunity cost perspective of the strategy into the selection of decision-making strategy, it is possible to retain farmers by supporting and developing individual farmers and making their income from agricultural operations not lower than or even higher than the income of migrant workers. The development of "family farms" was first proposed by the central document in 2013, followed by central document from 2014 to 2016, which continued to emphasize the development of family farms. In addition, the Ministry of Agriculture issued a special "guidance on promoting the development of family farms" to further emphasize the significance of the development of family farms, features, supportive policies and development measures in 2014. With the support of governments at all levels, family farms have sprung up. But the essence of family farms is the specialized large farmers (Kong \& Mao, 2013). Under the constraints of agricultural natural risk and market risk, it is still difficult for family farms to go to market in a good way, and it is still necessary to cooperate with agricultural enterprises or farmers' cooperatives.

At present, the agricultural competition is the competition of the agricultural industrial chain. Under various institutional constraints, it is difficult for a single management entity to obtain the core competitiveness of the industrial chain alone. All kinds of agricultural management entities need to participate in the division of labor and cooperation of industrial chain based on their own resource endowment advantage, and formed new integrated agricultural management entities, such as: "company + famers", " cooperative + famers " or "company + cooperative + famers ", which would enhance the survival of the partners and the international competitiveness of Chinese agriculture. Although the interests of cooperative farmers are often exploited by leading organizations, it is undeniable that agricultural enterprises and cooperatives, as an important agricultural management entity, can play a leading role in the AIM and promote the increase of cooperative farmers ' income. In the macroscopic view, taking Guangdong Province as an example, there were 17,215 agricultural industrialization organizations built, which led to 5.576 million households go on this, with an increase of 2196 yuan every year on average for one householder income in 2010. And, the leading enterprises were 2,325, driving 3.86 million households, with an average annual increase of 2,823 yuan on average for one householder income. The farmers' cooperatives were 6,715 , and the average annual income of farmers is more than $15 \%$ higher than that of other farmers in the cooperatives (Guangdong Yearbook, 2011). Another data show that there were 386,000 agricultural industrialization organizations, which driving 126 million farmers and the average income for one household has been increased to 3380 yuan at the end of 2015. The key agricultural leading enterprises above the provincial level will return or distribute more than 300 yuan of profits to each household in 2015 (Xin, 2015). The 
empirical study from Wang et al. (2008) shows that the leading enterprises of agricultural industrialization have significant radiation driving ability, the more the number of leading enterprises of agricultural industrialization in a region, the larger the scale is and the higher the per capita net income of farmers. The study of 481 apple farmers from Ma and Abdulai (2016) found that farmers' joining cooperative could increase their apple yield, agricultural net income and household income effectively, which were $5.36 \%, 6.06 \%$ and $4.66 \%$, respectively. However, the profit-oriented hierarchical management entities will only selectively drive the relatively rich resource endowment farmers, the resource endowment poor farmers are often excluded from the cooperative system. Many of these non-cooperative farmers are poor in rural areas and they need to be supported urgently.

The national policy of AIM not only aim to increase the income of cooperative farmers in the industrial system, but also hope that leading organizations can lead non-cooperative in terms of knowledge, technology, information and increase their income. This paper describes the driving role of leading organizations in non-cooperative farmers as the spillover effect of agricultural industrialization. In reality, there are some examples of the spillover effect in relatively small areas. For example, Guangdong Wenshi Group has played a role in promoting the development of non-cooperative farmers in many villages and towns. However, to what extent does this spillover effect of AIM exist? Under the background of realizing the hard restriction of lifting out of poverty at the end of the 13th Five-Year Plan period, the study on the spillover effect of AIM may be of enlightening significance in promoting the poverty alleviation of industry and obtaining the development for weak farmers.

\section{A Theoretical Study on the Existence of Spillover Effect}

From the perspective of organizational structure, there are two kinds of agricultural management entities in our country. One is the ones without formal organizational structure and without organizational hierarchy, which are essentially similar to the individual system of business ownership, represented by small farmers, large farmers (specialized large farmers, family farms). Their production scale is generally small, and do not have the organizational advantage based on specialized division of labor, and the ability to collect and sort out market information and control the market is relatively poor. The other is the ones existence of formal organizational structure with organizational hierarchy. They are essentially belonging to the cooperative system or the corporate system, farmers' cooperatives, agricultural enterprises as a representative, which is called the HAME. Except that the law stipulates that it belongs to the state or has been collected according to law, the rural land belongs to the collective ownership. HAME can not enjoy the ownership and contract right of the land, but they can only cooperate with the farmers of the land contract right to carry out the agricultural management. In addition, agricultural production and natural life process intertwined together, the periodic growth of animals and plants lead to seasonal agricultural production process, thus it creating intermittent demand for labor factors input. It is difficult for the labor elements of the HAME to match them completely without idling, while the farmers can adapt to the busy agricultural idleness at a lower opportunity cost (Wan \& Ou, 2010). Furthermore, the growth of animals and plants is a continuous process, which makes the management performance of agricultural production process difficult to be divided and evaluated. That is to say, in the process management of agricultural production, the farmers have a comparative advantage over the management of agriculture. Therefore, in the division of labor of the agricultural industrial chain, farmers often choose to care for the production process of plant and animal growth actively or passively.

As the HAME, agricultural enterprises have the authoritative mechanism of resource allocation of saving transaction cost, and they have the specialized research and development, operation and marketing team with obvious advantage of division of labor. The advantages are obvious in the combination and allocation of agricultural production factors, development and training of production technology, which deeply processing and circulation of agricultural products. The ability to defuse epidemic disease, avoid natural disasters and control market risks are very good (Wan \& Ou, 2010). It has become the leading force of AIM to increase the income of cooperative farmers in China. As a mutual-aid economic organization based on service members, farmers' cooperatives can effectively connect and disperse farmers in the production process, provide production, sales and information services for the member farmers, guide the farmers to carry out production activities based on market demand, and reduce the transaction costs of farmers entering the market (Cai, 2011). This would improve the market position of farmers (Chen, 2013). Some of the better cooperatives can also participate in cooperation with agricultural enterprises or even to build their own agricultural processing enterprises to extend the industrial chain, enhance the added value of agricultural products, help member farmers share the profits from processing, sales and other links, increase members farmers' income. In view of the different advantages of various agricultural management entities, the integration and development trend of both division of labor and cooperation in the agricultural industry chain are obvious, the "company + cooperative + farmers" management 
mode is becoming more and more common. In the "corporation + cooperative + farmers" mode, not only the horizontal cooperation advantage between farmers which make up the cooperative, but also the competitive advantage of the value chain, which the corporation integrates other main bodies in the agricultural industry chain. Based on social networks, there are more cooperative tripartite cooperation to create residual advantages.

As China's rural areas are a traditional society, farmers lived adjacent to each other, and based on blood, kinship, geographical and other frequent communications, they are very familiar with each other. The important resources, such as finance, technology and information, can be embedded and mobiled in social networks (Kuang, 2014). In the process of dealing with the agricultural industrialization management entities, especially the cooperative farmers, the non-cooperative farmers can get the spillover effect of the technology, information or even capital of AIM. The questionnaires surveyed of 145 farmers from Ying and Zhu (2015) showed that there was technology diffusion benefit in agricultural technology training, and farmers who have not participated in agricultural technology training can learn and imitate the productive behavior of farmers who have participated in technology training in the same village. It makes the production behavior more reasonable than the production behavior of farmers who do not participate in agricultural technology training in neighboring villages. The empirical study on 256 family farms from Zhang et al. (2014) showed that leading agricultural enterprises had knowledge spillover effects on the family farms with higher organizational proximity and knowledge proximity, which could promote the development of family farms. As far as pure farmers are concerned, the income of cooperative farmers in AIM is generally higher than that of non-cooperative farmers. The extensive loans between relatives, friends and neighbors in rural areas can show more or less capital spillover effects.

In the process of AIM, although all kinds of leading organizations and farmers concluded the overall stability of the alliance, it can not be ignored that many cooperative farmers separated from the industrialized management organizations into non-cooperative farmers, a few of them later become cooperative farmers (Wan \& Ou, 2011). These non-cooperative farmers have already obtained the spillover effects in technology, management, information.

Various industrialization organizations have driven 124 million households in China in 2014 (Chinese Ministry of Agriculture \& China agricultural yearbook, 2015), However, about half of the farmers are still scattered outside industrial management. Is there any spillover effect that benefits the farmers outside the AIM system? This paper tries to make an exploratory study of this problem.

\section{Research Design}

\subsection{Research Methods}

According to the type of driving farmers, the industrialization management performance of HAME includes two aspects: one is directly driving the performance of cooperative farmers; the other is driving the performance of non-cooperative farmer, namely spillover effect referred to in this paper. Because the spillover effect of AIM is difficult to be measured directly, this paper uses the total amount method and residual value method to subtract the proven AIM performance from the total amount of agricultural performance. That is, the spillover effect of AIM to be measured. If the total agricultural management performance is related to the level of development of HAME, it indicates that there may be spillover effect. If the total agricultural management performance is not related to the level of development of HAME, or the correlation is not significant, it can be inferred that the spillover effect of HAME is very limited, or even not.

\subsection{Variable Selection}

(1) Explained variables. Limited by the availability of data, this paper uses the farmers per capita total agricultural output value and farmers per capita household operating income to measure the performance of agricultural management in various regions.

(2) Explain variables. The level of development of the HAME is mainly reflected in the two dimensions of quantity and development quality of the management entities. Considering the original policy intention of AIM, and the data availability constraints, this paper uses the driving ability of the HAME to measure its development quality. In addition, due to the lack of statistical data of the HAME, and coupled with the agricultural enterprises and cooperatives are the most important two types of HAME at this stage, agricultural enterprises and cooperatives are regarded as proxy variables of HAME in this paper. Among them, the number of agricultural enterprises and the number of farmers driven by agricultural enterprises are uncompleted in each provincial area. By now, we only can get the relevant data of key agricultural leading enterprises above the provincial level. Key agricultural leading enterprises above the provincial level are the "outstanding ones" in agricultural enterprises, which play a leading role in the development of agricultural industrialization in various places. Their quantity 
and the number of farmers driven by them can reflect the overall management situation of agricultural enterprises in various regions to a certain extent. Therefore, this paper uses the number of key agricultural leading enterprises and cooperatives above provincial level and their respective driving ability to measure the level of development of regional HAME. Specific indicators include the number of key agricultural leading enterprises above the provincial level owned by each 10,000 agricultural population; the proportion of farmers driven by key agricultural leading enterprises above the provincial level in total farmers; the number of cooperatives owned by each 10,000 agricultural population; and the proportion of farmers driven by cooperatives in total farmers.

(3) Control variables. Existing related studies have confirmed that the factors influencing the performance of agricultural management in various regions mainly include the degree of marketization of the region (Meng \& Wu, 1998; Liu \& Xue, 2003), agricultural resources endowment (Kang, Wang \& Sun, 2013), and the level of fiscal support for agriculture (Wei, 2007; He \& Liu, 2015). Agricultural resource endowment mainly includes land, material capital and human capital, which are respectively using per capita arable land area, the original value of productive fixed assets, and rural labor force human capital measurement for measure. The variables and definitions are shown in the following Table 1.

Table 1. Variable Names and Definitions

\begin{tabular}{|c|c|c|c|}
\hline Variable category & Variable name & $\begin{array}{l}\text { Variable } \\
\text { code }\end{array}$ & Variable definition \\
\hline \multirow{2}{*}{$\begin{array}{c}\text { Dependent variables: } \\
\text { agricultural management } \\
\text { performance }\end{array}$} & $\begin{array}{l}\text { Farmers per capita } \\
\text { agricultural output value }\end{array}$ & FOU & - \\
\hline & $\begin{array}{l}\text { Farmers per capita household } \\
\text { operating income }\end{array}$ & FOI & - \\
\hline
\end{tabular}

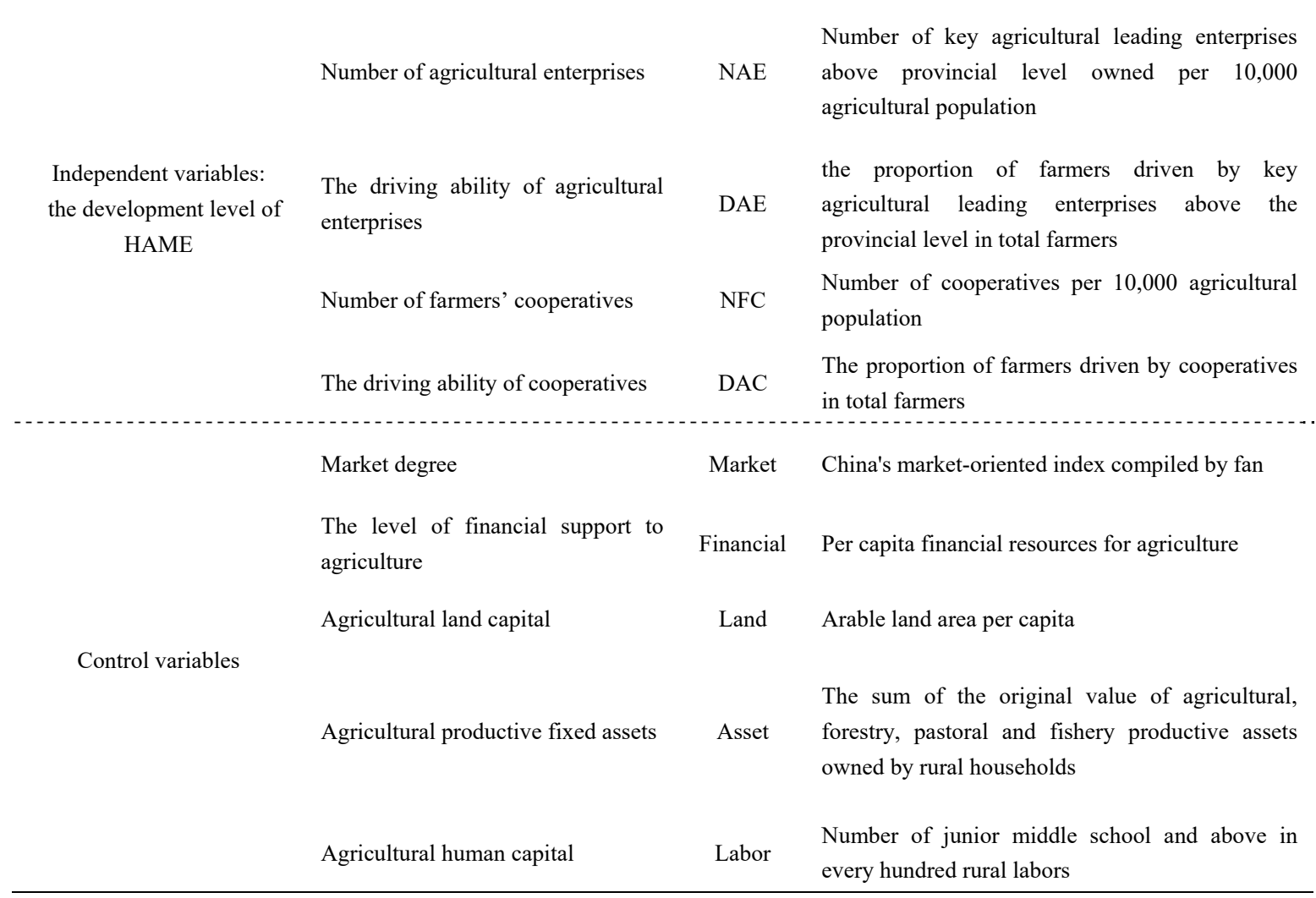

\subsection{Sample Selection and Data Sources}

(1) Sample selection. In view of large difference between municipalities and other provinces in the geographical area, agricultural output ratio and per capita GDP, this paper excludes the data of the four municipalities under the Central Government. Due to the limitations of statistical data collection, this paper selected 20 provincial 
district data for 2010 as research samples.

(2) Source of data. Data on agricultural performance and financial support for agriculture were derived from the 2011 China Statistical Yearbook. The data of the development of HAME is based on the agricultural yearbooks of the provincial administrative regions, the Chinese Agricultural Yearbook, and the Chinese Agricultural Yearbook. The dates were collated from the "Eleventh Five-Year Plan" report on the Development of Agricultural industrialization compiled by the Ministry of Agriculture and the data published on the website of the Department of Agriculture of various regions. The data of the degree of marketization comes from "China marketization Index-relative process of marketization of various regions in 2011", which is compiled by Fan Gang. The data of agricultural resource endowment comes from "China Rural Statistical Yearbook" in 2011.

\subsection{Model Setting}

Based on the above analysis, this paper constructs two multiple regression models as follows:

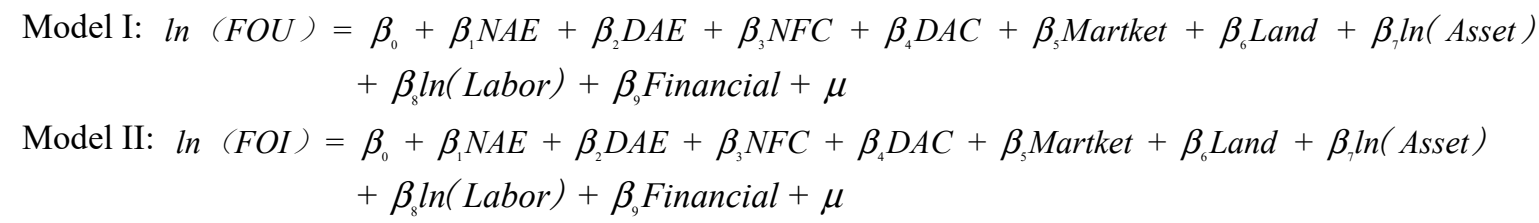

\section{Empirical Study}

\subsection{Correlation Analysis}

The correlations analysis between the main variables is shown in Table 2. From the correlation coefficient, there is no significant consistency between the four indicators of the development level of HAME and the performance of agricultural management. The driving ability of key agricultural leading enterprises above the provincial level, the number of cooperatives owned by every ten thousand agricultural population and the performance of agricultural management has a significant positive correlation. There is no significant correlation among the number of key agricultural leading enterprises above the provincial level, the driving ability of cooperatives and the performance of agricultural operations per ten thousand agricultural populations. This means that the relationship between the development level of HAME and the regional agricultural management performance are not strong, and the spillover effect of AIM may be very little.

Table 2. Pearson correlations coefficient

\begin{tabular}{|c|c|c|c|c|c|c|}
\hline & $\ln (\mathrm{FOU})$ & $\ln (\mathrm{FOI})$ & NAE & DAE & NFC & DAC \\
\hline $\ln (\mathrm{FOU})$ & 1 & & & & & \\
\hline NAE & 0.199 & 0.205 & 1 & & & \\
\hline DAE & $0.399 *$ & $0.513 * *$ & 0.312 & 1 & & \\
\hline DAC & 0.049 & 0.177 & $0.424^{*}$ & $0.669 * * *$ & $0.727 * * *$ & 1 \\
\hline
\end{tabular}

Note. $*, * * * * *$ represent significant levels of $\mathrm{P}<0.1, \mathrm{P}<0.05, \mathrm{P}<0.01$, respectively.

\subsection{Regression Analysis}

In order to have a further explore on the effect of explanatory variables for the explained variables, the regression analysis was carried out using the SPSS19.0 statistical software, and the regression results are shown in Table 3 
Table 3. Results of Multiple Regression

\begin{tabular}{lll}
\hline & Model I: ln (FOU) & Model II: ln (FOI) \\
\hline NAE & -0.942 & -0.320 \\
DAE & $2.090^{*}$ & 1.426 \\
NFC & -0.026 & -0.006 \\
DAC & $-2.907^{*}$ & -0.560 \\
Market & 0.054 & $0.070^{*}$ \\
Land & $-0.092^{*}$ & -0.009 \\
ln(Asset) & $0.396^{* *}$ & $0.479 * * *$ \\
ln(Labor) & $1.696 * * *$ & 0.427 \\
Financial & $0.540^{* *}$ & -0.050 \\
Adj.R & 0.835 & 0.737 \\
F Test & $11.672^{* * *}$ & $6.906^{* * *}$ \\
Durbin-Watson & 1.523 & 1.667 \\
\hline
\end{tabular}

Note. $*, * * * * *$ represent significant levels of $\mathrm{P}<0.1, \mathrm{P}<0.05, \mathrm{P}<0.01$, respectively.

Both the two regression models passed the F test, which showed that the two models were significant. DW test values are close to 2, which indicating that there is no obvious autocorrelation in the regression model. The expansion coefficients (VIF) are less than 10, which indicating that there is no serious multi-collinear problem in the model. The Spearman grade correlation coefficient between independent variable and absolute residual value is not 0 at $5 \%$ confidence level, which indicates that there is no heteroscedasticity in the model. Therefore, the results of the two regression models are credible.

According to Table 3, the number of key agricultural leading enterprises and cooperatives owned by every ten thousand agricultural population has no significant effect on the performance of agricultural management, that is, the number of HAME has no significant effect on the performance of agricultural management. This shows that the agricultural management entities promoted by government support policies at all levels are intermingled with good and bad, the performance assessment system favoring quantitative indicators needs to be optimized, and the development quality of HAME should be paid more attention. Coincidentally, there is no statistical correlation between the two indicators of driving ability of measuring the quality of development and the per capita household income of farmers. It can not be ignored the phenomenon of "crowding out effect" proposed by Li(2012) that enterprises enclose land to build "big parks", which makes it more difficult to increase income for the vast majority of farmers who rely on family management to be uncompetitive. Since enterprises and cooperatives have driven the income of cooperative farmers, the existence of crowding out effect makes the income of non-cooperative farmers more difficult. The two offsets may make the two indicators of driving ability of this paper and the per capita household operating income of farmers show no obvious correlation. In addition, it is worth noting that agricultural enterprises are a large group, in addition to provincial and above key agricultural leading enterprises, there are prefecture-level, county-level key agricultural leading enterprises. Meanwhile, a large number of small and medium-sized agricultural enterprises have not been selected as at all levels of key agricultural leading enterprises. Due to the different relative importance of agriculture in different regions and the different preferences of local leaders for "grasping hands" in economic development, the efforts to cultivate key agricultural leading enterprises above the provincial level are varying greatly. Perhaps a large number of prefecture-level, county-level key agricultural leading enterprises and other small and medium-sized agricultural enterprises have more advantages in promoting the income increase of farmers in specific regions.

The driving ability of key agricultural leading enterprises above provincial level had a significant positive effect on per capita gross agricultural output value $(\beta=0.603, \mathrm{P}<0.001)$. The key agricultural leading enterprises above the provincial level have been the keys to promote regional agricultural industrialization. As early as ten years ago, there were 209 key agricultural leading enterprises above the provincial level in Sichuan, with an average sales income of 150 million yuan, accounting for $33.5 \%$ of the total number of farmers in the province (Tang \& Guo, 2006). The provincial and above key agricultural leading enterprises have developed rapidly in the past ten years. Take the national agricultural leading enterprises as an example, the notice of the Ministry of Agriculture on the announcement of the seventh monitoring of qualified agricultural industrialization list of key national leading enterprises in October 2016 shows. There are 1131 national key leading enterprises in agricultural industrialization monitoring qualified. This means that since the end of 2012, the 5th batch of state-level key leading enterprises were announced, a total of 122 enterprises have lost their qualification for the 
state-level key leading enterprises in agricultural industrialization because of their unqualified monitoring. However, in 2016, the National Joint Conference on Agricultural industrialization decided to fill 111 enterprises as key national leading enterprises in agricultural industrialization. Therefore, the total number of key state agricultural leading enterprises is 1242 , which is more than twice to the numbers by the end of 2005 . Not only the national agricultural leading enterprises develop rapidly, but also the provincial agricultural leading enterprises grow rapidly. The number of leading enterprises increased from 81,500 at the end of 2008 to 129,000 at the end of 2015. The sales revenue of various leading enterprises in China reached 9.2 trillion yuan in 2015 (Xin, 2016). The value added of the primary industry in the whole year was more than 1.5 times that of 6087.05 billion yuan. Agricultural leading enterprises have been the main force of regional agricultural growth.

The driving ability of cooperatives had a negative effect on the per capita gross agricultural output value ( $\beta=$ $-0.289, \mathrm{P}<0.01$ ), but the relationship between the driving ability and the per capita household income of farmers was not significant. On the one hand, it suggests that cooperatives may be crowding out the living space of non-cooperative farmers. At present, there is structural imbalance between supply and demand of agricultural products in China. There are more agricultural products, less processed agricultural products, more ordinary agricultural products, less characteristic agricultural products, more low-end agricultural products and less brand agricultural products. The stronger the driving ability of cooperatives, the more able to carry out early processing of agricultural products, agricultural product safety certification and brand building business, and meet market demand for agricultural products. Even if non-cooperative farmers can obtain market information through cooperative farmers, but due to the limitations of their own resource endowment, it is difficult to produce agricultural products that meet market demand. The sales of agricultural products are vulnerable to the squeeze of cooperative high-quality agricultural products. This undoubtedly affects its enthusiasm to increase the supply of effective agricultural products. On the other hand, under the pressure of the government at all levels to grasp the construction of cooperatives by means of monthly report data, the number of farmers driven by cooperatives reported by the agricultural departments in some areas is false, and the extent of this data is obvious difference between regions. To some extent, it makes the cooperative's driving ability lose its due correlation with the per capita gross agricultural output value and the per capita household operating income of farmers.

Overall, the development level of HAME has not obvious positive effect on the performance of agricultural management. Perhaps, because of the existence of crowding out effect, even if there is spillover effect in agricultural industrialization, the net spillover effect after subtracting the spillover effect in a particular region is very little. This paper does not discuss the crowding out effect does not mean that we do not pay attention to the crowding out effect, but the spillover effect refers to the net spillover effect after deducting the crowding out effect. In order to increase the net spillover effect, it is necessary to reduce the crowding out effect, which means that the government policy for a long time to support the leading organization of agricultural industrialization needs to be optimized. The policy needed to give more support to the weak farmers outside the industrialization management system, which is urgent and important in the realistic situation of building a well-off society in an all-round way.

In the control variables, agricultural productive fixed assets have a significant positive effect on agricultural management performance. Agricultural human capital and financial support level have a significant positive effect on per capita gross agricultural output value. It shows that China's agriculture is still in the factor input-driven stage, human and capital inputs factors for agricultural growth play an important role in the benefits of the people, however, the high production cost of agricultural products, the decline of international competitiveness of agriculture and other risks continue to accumulate, agricultural development needs to convert kinetic energy. The arable land area per capita has a significant negative effect on the per capita gross agricultural output value, which may mean that the pace of agricultural transformation and upgrading in the regions with relatively rich arable land resources is slower, and it is obvious for the path dependence of agricultural growth based on the advantage of arable land resources. The adjustment of agricultural structure in areas with relatively little cultivated land resources is fast, and the effect of agricultural production increase is more obvious. The marketization degree has a significant positive effect on the per capita household operating income, which confirms the superiority of the market allocation of resources.

\section{Further Discussion}

Based on the theoretical deduction, it is possible to have some spillover effect on the agricultural industrialization, because of the interconnection of the rural society and the greater closeness. However, the empirical research results show that the spillover effect of agricultural industrialization is very little, and multiple indices show no spillover effect on the significant level. This is due to the availability and limitation of data, which makes the research conclusions have limitations, but the more important explanation is that the crowding 
out effect offsets the spillover effect in a large extent so that the net spillover effect is not obvious.

Since the beginning of agricultural industrialization, China has been implementing the policy of supporting agriculture and farmers. The original intention of this policy is very good, also played a role. But it can not be overlooked that a considerable number of small and weak farmers are excluded from the AIM system, and by the agricultural industrialization of the squeeze makes it more difficult to increase income. The existence of this kind of crowding out effect accelerates the differentiation of farmers within and outside the industrialized management system. In the 2016, China has completed more than 10 million rural poverty eradication tasks, but there are still more than 40 million rural poor people desperately need to get rid of poverty. In the future, the government should intensify its efforts to support the farmers outside the industrialized management system, and focus on guiding social capital to the relatively backward rural areas for the alleviation of industry. Only in this way, we can rely on the power of many and build a well-off society of the short board as soon as possible.

At present, the academic circle pays more attention to the research of the impetus effect within the AIM system, lacks the attention of the crowding out effect on farmers who are outside the system, but the crowding out effect is very important in the reality and needs the academic research topic. This paper looks forward to attract more scholars devoted to study the crowding out effect and spillover effect of AIM.

\section{Acknowledgments}

The authors are gratefully acknowledge support from the Key Project of National Social Science Fund Project of China (14AJY020 and 16AJY015) and High-level Talent Project in Colleges and Universities of Guangdong Province(Guangdong Finance Education [2013] No. 246).

\section{References}

Cai, R. (2011). "Cooperatives + farmers" model: the effect of transaction cost saving and farmers ' income--an empirical analysis based on the questionnaire survey of Apple farmers in Shandong Province. China's Rural Economy, (1), 58-65.

Chen, X. W. (2013). Constructing new agricultural management system and speeding up the development of modern agriculture. Economic Research, (2), 4-6.

China's Ministry of Agriculture. (2015). Agricultural Yearbook of China. Beijing: China Agriculture Press.

Guangdong Yearbook. (2011). Guangdong Yearbook: 2011. Guang Zhou: Guangdong Yearbook Society Press.

He, Z. L., \& Liu, C. Y. (2015). Study on factors influencing agricultural productivity and efficiency in China: An empirical analysis based on three-stage DEA model. Rural Economy, (6), 48-51.

Kang, X., Wang, G. S., \& Sun, Z. R. (2013). Evaluation of input-output efficiency of agricultural production resources in main grain producing areas. Technology and Economy, (3), 41-45. 10.3969/j.issn.1003-2053.2014.10.010

Kong, X. Z., \& Mao, F. (2013). The connotation, main body and promotion strategy of agricultural modernization. Agricultural Economy and Management, (2), 9-15. 10.3969/j.issn.1674-9189.2013.02.002

Kuang, H. Y. (2014). The relationship between rural social network and agricultural technology diffusion--a case study of the spread of swine technology in G Township. Journal of scientific Research, (10), 1518-1524. $10.3969 / \mathrm{j}$.issn.1003-2053.2014.10.010

Li, Q. (1998). Several problems of developing agricultural industrialization management. China's Rural Economy, (12), 40-45.

Liu, Q. (2012). From "Being upstairs" to "being scaled". China Development Observation, (10), 45-48. 10.3969/j.issn.1673-033X.2012.10.016

Liu, Y. J., \& Xue, J. X. (2003). Speeding up the process of agricultural marketization is the basic way to increase farmers ' income. Economists, (1), 68-73. 10.3969/j.issn.1003-5656.2003.01.010

Ma, W., \& Abdulai, A. (2016). Does cooperative membership improve household welfare? Evidence from apple farmers in China. Food Policy, (58), 94-102. https://doi.org/10.1016/j.foodpol.2015.12.002

Meng, X., \& Wu, H. X. (1998). Household income determination and regional income differential in rural China. Asian Economic Journal, 12(1), 35-63. https://doi.org/10.1111/1467-8381.00052

Niu, R. F. (1997). Theory and practice of integrated management of agricultural industry. Economic Research Reference, (54), 2-21. https://doi.org/10.16110/j.cnki.issn2095-3151.1997.54.001

Pan, J. (2011). Chinese farmers ' professional cooperatives: an interpretation behind the data. Chinese rural 
Observation, (6), 2-11.

Sun, Y. F., \& Yu, H. P. (2012). Analysis on the development status and operation mechanism of farmer specialized cooperatives after legislation--based on the research data of Jiangsu Province. Agricultural Economic Problems, (2), 89-96. https://doi.org/10.13246/j.cnki.iae.2012.02.017

Tang, M. P., \& Guo, Z. H. (2006). Analysis on financing problems of leading enterprises in agricultural industrialization--based on the research of 150 provincial-level leading enterprises in Sichuan Province. Rural Economy and Science-Technology, (10), 62-63. https://doi.org/10.3969/j.issn.1007-7103.2006.10.031

Wan, J. Y., \& Ou, X. M. (2010). Industrial chain integration, earmarked investment and cooperation surplus allocation: an example from Wen's model. China's rural economy, (5), 28-42.

Wan, J. Y., \& Ou, X. M. (2011). Social embedding, Difference order governance and contract stability--a case study based on the east-model. China's rural economy, (7), 14-24.

Wang, A. Q., Xia, Y., \& Qin, Y. (2008). An empirical analysis of the radiation capacity of the leading enterprises in agricultural industrialization in Jilin Province. Agricultural Resources and Regionalization in China, (2), 48-53.

Wei, L. (2007). Study on the impact of financial support expenditure on agricultural economic growth in China--an empirical analysis of the contribution rate of agricultural production in 1999-2003. Journal of Central University of Finance and Economics, (9), 11-16, 22.

Xin, W. (2016 August 5). The total number of agricultural industrialization organizations reached 386,000 in China in 2015. China cooperation Times, p. A4.

Ying, R. Y., \& Zhu, Y. (2015). The influence of agricultural technical training mode on farmers' agricultural chemicals use behavior--evidence from experimental economics. Chinese rural Observation, (1), 50-58, 83, 95.

Zhang, Y. Q., Cai, Z., \& Zhang, L. (2014). Study on knowledge spillover effect of agricultural leading enterprises on family farms--a case of Heilongjiang province. Agricultural Economic Problems, (11), 10-16. https://doi.org/10.13246/j.cnki.iae.2014.11.002

\section{Copyrights}

Copyright for this article is retained by the author(s), with first publication rights granted to the journal.

This is an open-access article distributed under the terms and conditions of the Creative Commons Attribution license (http://creativecommons.org/licenses/by/4.0/). 